\title{
A mudança institucional da OTAN no pós- Guerra Fria: uma análise da evolução do Conceito Estratégico a partir do modelo de Mahoney e Thelen
}

\begin{abstract}
NATO's institutional change in the post-Cold War: an analysis on the evolution of the Strategic Concept in the perspective of Mahoney and Thelen's model

El cambio institucional de la OTAN en la era posterior a la Guerra Fría: un análisis de la evolución del Concepto Estratégico utilizando el modelo de Mahoney y Thelen
\end{abstract}

Vlademir Monteiro'

$<$ ? > Doutorando no Programa de Pós-Graduação em Ciência Política da UFPE. Residente em João Pessoa, Brasil. Membro do Núcleo de Estudos Americanos e do Grupo de Pesquisa em Estudos Estratégicos e Segurança Internacional. Áreas de interesse: Segurança Internacional, Teoria das Rl, Oriente Médio. Orcid: https://orcid.org/00000002-2800-6194
DOI: 10.5752/P.2317-773X.2021v9.n2.p132

Recebido em: 29 de abril de 2020

Aceito em: 12 de outubro de 2020

\begin{abstract}
Resumo
Este artigo discute o impacto da reformulação, no pós-Guerra Fria, do Conceito Estratégico no arcabouço normativo da OTAN. O Conceito Estratégico prescreve as diretrizes e as práticas que norteiam a conduta da organização. Desde o desmantelamento da ordem bipolar, foram elaborados três documentos desse tipo - um em 1991, outro em 1999 e o mais recente em 2010 e cada um deles introduziu novidades no tocante à função, o escopo e área de atuação da Aliança Atlântica, enquanto também preservou outras regras. Diante do exposto, pretende-se explicar esse processo sob a ótica do estudo de Mahoney e Thelen acerca da mudança institucional. O objetivo é analisar como o CE impacta a trajetória evolutiva da entidade e como os conflitos de interesses nos quais sua elaboração se insere formatam o conteúdo de cada versão e o tipo de mudança. Em termos metodológico, o trabalho se estrutura como um estudo de caso único, que recorre ao exame de documentos oficiais e o uso de fontes secundárias. Entre os resultados, se constata que a trajetória de mudança na OTAN é marcada por revisões substanciais em suas atribuições funcionais e uma dilatação de seu alcance geográfico.
\end{abstract}

Palavras-chave: Mudança institucional. OTAN. Conceito Estratégico.

\section{ABSTRACT}

This article addresses the impact of the post-Cold War reformulation of the Strategic Concept on NATO's normative framework. The Strategic Concept 
prescribes the norms and practices that guide the organization's conduct. Since the dismantling of the bipolar order, three such documents have been drawn up - one in 1991, another in 1999 and the most recent in 2010, and each of them have introduced new features regarding the scope and area of action of the Atlantic Alliance, while also preserving others rules. In view of the above, this piece of work intends to explain this process from the perspective of Mahoney and Thelen's study about institutional change. The main purpose is to analyze how the SC impacts the organization evolution and how the interests conflicts shapes the SC content and type of the change. In methodological terms, the work is structured as a single case study, which uses the examination of official documents and the use of secondary sources. Among its findings, the article finds out the NATO's trajectory of chance is marked by the reformulations over its functions and widening of its geographic reach.

Keywords: Institutional chance. NATO. Strategic Concept.

\section{RESUMEN}

Este artículo analiza el impacto de la reformulación del concepto estratégico posterior a la Guerra Fría en el marco regulatorio de la OTAN. El Concepto Estratégico prescribe las pautas y prácticas que guían la conducta de la organización. Desde el desmantelamiento del orden bipolar, se han elaborado tres documentos de este tipo: uno en 1991, otro en 1999 y el más reciente en 2010, y cada uno de ellos introdujo novedades sobre la función, el alcance y el área de operación de la Alianza Atlántica, al tiempo que también preservado otras reglas. Dado lo anterior, intentamos explicar este proceso desde la perspectiva del estudio de Mahoney y Thelen sobre el cambio institucional. El objetivo es analizar cómo la CE impacta la trayectoria evolutiva de la entidad y cómo los conflictos de intereses en los que se inserta su elaboración configuran el contenido de cada versión y el tipo de cambio. En términos metodológicos, el trabajo está estructurado como un estudio de caso único, que utiliza el examen de documentos oficiales y el uso de fuentes secundarias. Entre los resultados, se puede ver que la trayectoria de cambio en la OTAN está marcada por revisiones sustanciales en sus atribuciones funcionales y una expansión de su alcance geográfico.

Palabras clave: Cambio institucional. OTAN. Concepto Estratégico.

Introdução

A derrocada da Guerra Fria engendrou intensos questionamentos sobre a Organização do Tratado do Atlântico Norte (OTAN). Os debates pautavam o futuro da instituição, vis-à-vis um cenário em que a ameaça soviética havia se extinguido. De um lado, se argumentava que ela estava fadada a desparecer ou cair na insignificância, pois perdera sua utilidade (MEARSHEIMER, 1994; WALTZ, 1979). De outro, sustentava-se que tal conjuntura dificilmente se concretizaria, haja vista que os Estados europeus apreciavam os bens públicos providos para a manutenção da estabilidade e paz (MCCALLA, 1996). Transcorridas quase quatro décadas desde então, a aliança continua de pé. No entanto, sua sobrevivência se efetuou com o advento de funções e normas que, originalmente, não se encontram previstas no documento fundador da organização, o Tratado de Washington (TW).

O instrumento viabilizador dessa evolução foi o Conceito Estratégico $(\mathrm{CE})$. Este prescreve as diretrizes e as práticas que orientam 
a conduta da OTAN. Desde o término da Guerra Fria, foram elaborados três documentos desse tipo - um em 1991, outro em 1999 e o mais recente em 2010. A necessidade de formulá-los advém dos eventos que transcorrem no ambiente internacional, cujos efeitos impõem desafios e constrangimentos à segurança não apenas de alguns membros, mas da aliança como um todo. Diante disso, torna-se imperativo à organização revisar ou, inclusive, adotar preceitos para que possa continuar cumprindo com sua tarefa primordial: defesa coletiva. Do ponto de vista teórico, tal processo pode configurar o que a literatura denomina de mudança institucional. Um dos trabalhos mais profícuos sobre a temática foi desenvolvido por Mahoney e Thelen (2010). Seu modelo analítico identifica como fatores indutores dessa dinâmica o contexto político em que ela ocorre e as características da instituição (isto é, as regras). Ambos criam condições suis generis das quais emergem categorias, também, particulares de mudanças.

Ao se analisar as versões do $\mathrm{CE}$ introduzidas nas últimas quatro décadas, fica evidente a adaptação tanto funcional quanto normativa da OTAN, ainda que ela tenha preservado seu núcleo de princípios. O que endossa essa constatação são dois aspectos: (1) a aliança arrogar para si tarefas como prevenção de conflitos e gerenciamento de crises; (2) expandir sua atuação para fora de área euro-atlântica. Diante do exposto, o artigo pretende explicar esse processo de transformação sob a ótica do estudo de Mahoney e Thelen (2010). O objetivo é analisar a evolução da entidade, tendo como argumento que esse processo reproduz a categoria que os autores designam conversion. Em um campo onde neorrealistas e institucionalista ainda detém a hegemonia explicativa sobre as instituições, estudos baseados em perspectivas não sistêmica podem expandir e aprofundar a compreensão epistêmica desse fenômeno. Em particular, este trabalho oferece um contraponto à tese realista de que OTAN se tornaria inútil, salientando sua capacidade de adaptar-se e inovar normativamente.

$\mathrm{O}$ artigo se divide em três partes. Primeiro, abordarei os princípios elementares do pensamento hegemônico das Relações Internacionais sobre cooperação e alianças na seara da segurança. Ainda que haja uma divergência entre essas ideias e a construção teórica aqui empregada no que diz respeito à problematização do fenômeno investigado, o exame das primeiras faz-se imprescindível no intuito de demonstrar que suas deficiências podem ser complementadas com alternativas. Em seguida, apresentarei o modelo teórico de mudança institucional idealizado por Mahoney e Thelen (2010). Não pretendo reproduzi-lo em sua íntegra. Todavia, será dado foco aos tipos de transformação e suas respectivas características. Depois, irei aplicar esse referencial ao caso em tela, analisando as três versões do Conceito Estratégico lançadas desde a década de 1990. Partindo do pressuposto que elas promovem um conversion, busco explorar seu impacto nas normas e como os conflitos de interesses que permeiam a articulação de cada documento moldam o curso evolutivo. Por fim, trarei as considerações finais. 
No universo teórico das RI, as duas correntes mais proeminentes apresentam pouca convergência - para não dizer nenhuma - quanto à cooperação e o papel de instituições no campo da segurança. Embora admita que os Estados possam ocasionalmente se unir em busca de objetivos comuns, a literatura realista tende a nutrir uma visão pessimista a respeito do fenômeno (GLASER, 1994; GRIECO, 1988; MEARSHEIMER, 1994). Quase sempre, os autores minimizam a probabilidade de sua ocorrência, ao passo que a tônica da política internacional, na visão deles, se define pela competição entre as unidades. Contudo, esse quadro deriva menos dos aspectos individuais dos Estados do que das feições que configuram a arena onde eles atuam. Ou seja, a ausência de uma autoridade superior no sistema internacional os impele a adotar um comportamento de autoajuda, o que impõe constrangimentos na forma como eles interagem. Nas palavras de Waltz (1979, p. 161) "a anarquia dessa ordem afeta fortemente a possibilidade de cooperação, a extensão de acordos sobre desarmamentos e a jurisdição das organizações internacionais".

A realidade anárquica acaba inibindo os esforços cooperativo em virtude das preocupações com os ganhos relativos e o risco de traição (GLASER, 1994). No que diz respeito aos ganhos relativos, Waltz (1979) lembra que é imperativo às unidades atentarem à distribuição dos benefícios decorrentes das atividades associativas, haja vista que essa dinâmica produz efeitos sobre sua posição no SI e, consequentemente, sua segurança. O acúmulo de ganhos por uma das partes eventualmente potencializa suas capacidades e suscita posturas agressivas que podem se transformar em ameaças aos demais. Grieco (1988, p. 498) consegue resumir a problemática nos seguintes termos: "the fundamental goal of states in any relationship is to prevent others from achieving advances in their relative capabilities". Ao abordar a problemática da traição, Mearsheimer (1994) salienta o peso desse fator sobre os cálculos dos Estados quando estes avaliam se engajar em negociações. Há sempre a suspeita de que eles podem ser explorados por potenciais parceiros.

O mesmo ceticismo também permeia a leitura realista das instituições. Na verdade, os teóricos as visualizam a partir de uma ótica utilitarista: são produto da distribuição de poder no sistema e consistem em instrumentos que as grandes potências empregam a fim de maximizar seus interesses (SCHWELLER; PRIESS, 1997). De acordo com Mearsheimer (1994, p. 13), "os Estados mais poderosos [...] criam e moldam as instituições para que eles possam manter sua parcela do poder mundial ou até mesmo aumentá-la”. Disso se depreende que sua existência está imbricada a power politics, de tal modo que sua sobrevivência é função da configuração de poder.

Não obstante esse panorama pessimista, no qual o conflito dita os rumos da política internacional, ocasionalmente as unidades se empenham em torno de um pleito que sirva a seus interesses. Um exemplo delas se encontra na formação de alianças. Um dos trabalhos mais seminais a respeito foi escrito por Stephen Walt (1987). Em The Origins of Alliances, 
o estudioso formula um esquema teórico no intuito de identificar e explicar as causas das coalizões estabelecidas pelos entes estatais. Segundo sua tese, esse expediente associativo constitui uma estratégia reativa às ameaças de natureza militar com que eles se defrontam, de modo que ele se apresenta em duas variantes. Uma delas corresponde ao balanceamento, no qual um Estado se vincula a outros a fim de enfrentar aquele que impõe algum perigo a sua segurança.

A outra variante toma a forma de um bandwagoning. Num caso desses, um Estado opta por garantir sua sobrevivência se juntando ao desafiador do status quo. Walt (1987) aponta que a conduta é motivada pelo desejo de apaziguar as aspirações expansionistas do contestador. Logo, sua execução busca evitar um possível ataque. Outra razão para adoção desse tipo de comportamento reside no interesse pelos espólios do conflito. Independentemente das idiossincrasias de cada estratégia, elas convergem em certos pontos: as alianças possuem um valor instrumental, ao passo que seu emprego se orienta por um cálculo puramente racional. Além disso, é importante salientar seu caráter temporário no tocante à duração. Parafraseando Mearsheimer (1994), os governantes enfrentam dificuldades para criá-las e mais ainda para mantê-las.

A visão dos liberais - sobretudo dos expoentes da vertente institucionalista - contrasta substancialmente com a narrativa realista sobre cooperação e instituições internacionais. A despeito desse antagonismo, os neoliberais concordam com alguns aspectos do repertório ontológico do realismo (JERVIS, 1999). Mais precisamente, admitem que a anarquia é a força ordenadora do sistema internacional, a partir da qual derivam um conjunto de constrangimentos à ação estatal. Por outro lado, entre eles se constata uma rejeição à inexorabilidade que os realistas imprimem a tal condição, como se as unidades não tivessem outra alternativa senão se submeter fatalmente aos imperativos estruturais. Mesmo num cenário hobbesiano, marcado pela ausência de uma entidade supranacional dotada de poderes coercitivos para punir transgressores, é possível atenuar o ímpeto da anarquia. Então, se observa na política internacional, inúmeros casos em que os Estados adotam uma postura coletiva para lidar com determinadas questões. Para Oye (1985)

\footnotetext{
[Dada a natureza do SI], a possibilidade de descumprimento de uma promessa pode impedir a cooperação mesmo quando ela resulta em ganhos. No entanto, em outros momentos, os estados realizam objetivos comuns através da cooperação, sob a anarquia. [Dessa forma] os governos frequentemente se vinculam a cursos de ação mutuamente vantajosos (OYE, 1985, p. 1).
}

Segundo Keohane (1984), o emprego de estratégias cooperativas pressupõe a falta de convergência entre as partes envolvidas. Dito de outro modo, suas atitudes não apenas seguem trajetórias antagônicas, mas também produzem efeitos que não passam despercebidos a um ou outro, dado que tais implicações colocam obstáculos na concretização de preferências. Em virtude disso, se instalam situações conflitivas, para cujo desfecho a cooperação se mostra como um dos, senão o instrumento mais eficiente. "[Essa prática] não deve ser vista como a ausência de conflito, mas sim como uma reação a conflitos ou conflitos em potencial. Sem o espectro do conflito, não há necessidade de cooperar" (KEOHANE, 1984, 
p. 52). Deduz-se, então, que seu fim último consiste em promover a acomodação das divergências oriundas das posições opostas assumidas pelas unidades. Isso configuraria o que Keohane (1984) define como coordenação de políticas. Na prática, ao identificarem uma zona em que seus interesses minimamente concordam, os Estados buscam fazer ajustes em sua conduta, a fim de atenuar os constrangimentos que impedem a efetivação de seus propósitos.

Uma das deficiências desse modelo reside em seu foco temático. Os críticos apontam que a agenda de pesquisa se dedicou predominantemente ao estudo da cooperação nas searas econômica e ambiental, enquanto que os assuntos securitários não receberam a mesma atenção. Inclusive, se argumenta que seu esquema ontológico nem se compatibiliza nem se aplica ao universo da segurança internacional (JERVIS, 1999; MEARSHEIMER, 1994). Do lado liberal, essas premissas se deparam com uma veemente contestação. Os pesquisadores, além de julgarem inapropriada a segmentação epistemológica em dois âmbitos, atestam ser totalmente exequível articular entendimentos sobre as problemáticas securitárias sob o prisma da cooperação. Nessa linha, Axerold e Keohane (1985, p. 226-227) dizem que "[embora] nota-se que assuntos militares apresentem as características associadas mais com a anarquia do que os assuntos econômicos, [...] isso não significa que as análises desses dois conjuntos de assuntos requerem duas analíticas distintas".

Ao contrário de seus adversários realistas, os representantes do pensamento liberal atribuem certa proeminência às instituições internacionais. Elas são consideradas essenciais num cenário colaborativo, porque operam como facilitador ou potencializador desse tipo de expediente. Endossando essa visão, Keohane e Martin (1995, p. 42) atestam que as "instituições podem fornecer informações, reduzir os custos de transação, tornar os compromissos mais credíveis, estabelecer pontos focais para a coordenação e, em geral, facilitar o funcionamento da reciprocidade". Até mesmo no campo da segurança, sua função não deve ser subestimada, como a teoria realista o faz tão ferrenhamente. Mediante esses arranjos, os países dispõem de um mecanismo mitigador de um dos ditames mais intrínseco da ordem anárquica - a incerteza. Efetivamente, graças às informações providos por eles, as intenções unitárias se tornam transparentes e, ao mesmo tempo, ficam mais previsíveis, o que diminui, portanto, as suspeitas hobbesianas (KEOHANE; MARTIN, 1995).

Mudança institucional: o modelo de Mahoney e Thelen

Além de ilustrar as concepções divergentes sustentadas por liberais e realistas sobre a cooperação no âmbito da segurança, o quadro acima demonstra que essa literatura cria uma dicotomia que resume o debate à relevância ou não dos arranjos institucionais. Esse reducionismo oculta sua deficiência de ferramentas analíticas para investigar as instituições de dentro para fora. A consequência disso é que eles não conseguem fornecer uma compreensão mais robusta a respeito da evolução institucional, sobretudo quando se manifesta paulatinamente. Por isso, há necessidade de recorrer a uma agenda de pesquisa dedicada a esse fim. 
Uma possível alternativa seria lançar mão da literatura neo-institucionalista. Contudo, esse arcabouço também se mostra limitado para a empreitada. Embora não haja dúvidas de que a área desenvolveu um profícuo e vasto conhecimento sobre as instituições, suas leituras a respeito da mudança nesses arranjos carregam compreensões semelhantes àquelas das tradições teóricas das RI. Dito em outras palavras, a evolução decorre de externalidades, que imprimem "reconfigurações institucionais radicais" (MAHONEY; THELEN, 2010, p. 2). A vertente sociológica, por exemplo, apesar de seu potencial em explicar continuidades no âmbito institucional, oferece poucas elucidações acerca das transformações endogenamente causadas. Os adeptos da escolha racional também. Já os institucionalistas históricos aderem é condicionada pelas situações críticas, responsáveis por oportunidades para Portanto, em virtude da carência de estudos mais sofisticados, as três escolas do neo-institucionalismo oferecem contribuições modestas no exame da problemática em tela, visto que não propõem um "um modelo geral de mudança, particularmente um que compreenda tanto as fontes exógenas e endógenas de mudança" (MAHONEY; THELEN, 2010, p. 7).

Diante dessas circunstâncias, trabalhos como o de Mahoney e Thelen (2010) visam suprir as lacunas do campo. Na verdade, a fim evitar os lapsos das correntes citados anteriormente, os autores formulam uma abordagem que retira o foco causal de elementos externos e o situa na dinâmica política. Seu modelo se constrói a partir de uma leitura distribucional das instituições. Ou seja, entende-se que elas estão inseridas em disputas por recursos e essas circunstâncias as moldam como instrumentos alocativos. À luz disso, as regras assumem uma função estruturante, posto que são responsáveis por definir parâmetros de distribuição e, como não são neutras, tampouco imparciais, podem favorecer alguns autores em detrimentos de outros.

Embora consiga vincular as transformações a uma gênese endógena, a perspectiva distribucional, segundo Mahoney e Thelen, necessita de incrementos, visto que "[primeiro], não especifica os diferentes modos de mudança que esse dinamismo [interno] permite ou desencadeia. [Segundo,] nem incorpora uma explicação para por que um tipo de mudança ocorre em vez de outro" (MAHONEY; THELEN, 2010, p. 14). Tendo essa carência em conta, seu modelo agrega o contexto político e as propriedades da instituição como indutores da dinâmica transformacional. A confluência dessas variáveis cria condições suis generis que geram categorias, também, muito particulares de mudança. Esse processo pode se efetuar através de três trajetórias causais (conforme ilustrado na Figura 1). Estas são moldadas pela estrutura institucional e as circunstâncias políticas, que não somente potencializam alguns agentes a engendrar uma guinada, mas também operam como constrangimento na escolha das estratégias empregadas para tal propósito. No entanto, o ponto central desse processo é seu impacto sobre o acervo normativo institucional. A depender do perfil do ator protagonista e do curso de ação que ele decida implementar, as regras podem sofrer uma ampla variedade de consequências - desde sua extinção até a assimilação de novas leituras. 
Figura 1 - Esquema explicativo dos tipos de mudança institucional

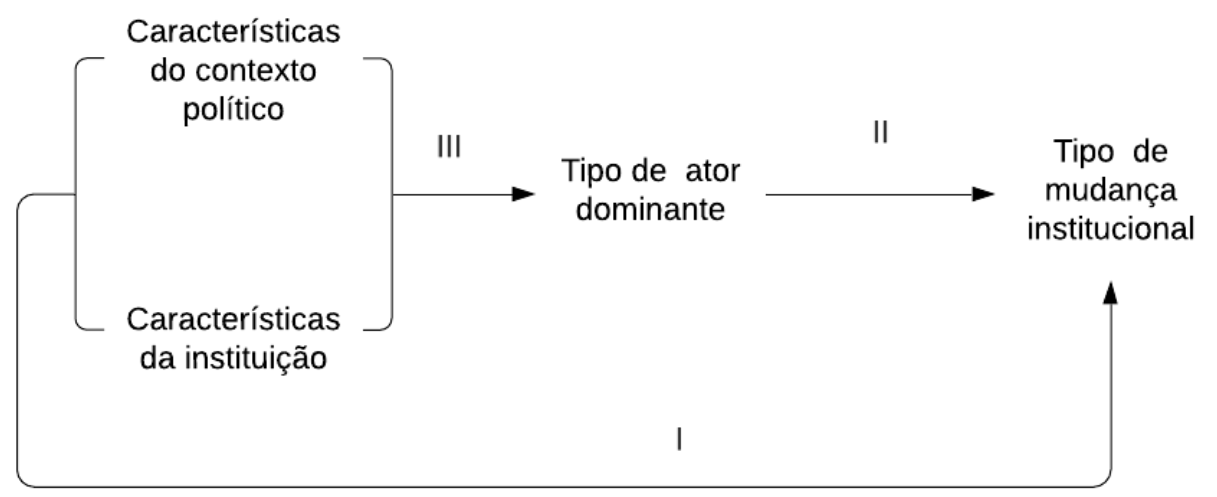

Fonte: adaptado de Mahoney e Thelen (2010)

Amparados nessas compreensões, os autores elaboram uma tipologia para classificar as mudanças (a Figura 2 esquematiza esses tipos). A primeira categoria engloba o displacement. Nele, observa-se a suplantação de antigas normas por novas. Normalmente, sua ocorrência tende a ser brusca e repentina - não por acaso, ele corresponde à transformação institucional ao redor da qual gravita a literatura hegemônica. A despeito desses aspectos, é possível também que seu desenvolvimento se efetue sob um ritmo mais dilatado no tempo. Nesse cenário, as regras existentes ainda persistem, ao passo que as instituições introduzidas não as substituem de imediato, nem definitivamente a curto e médio prazo. Pelo contrário, elas precisam competir com suas precursoras. Tal iniciativa emerge do jogo entre as forças políticas dentro de uma determinada ordem: quando a estrutura de um certo arranjo institucional não consegue atender a suas demandas, os agentes insatisfeitos emplacam posturas revisionistas. Do outro lado da arena, os favoráveis ao status quo dispõem de poucas capacidades para impedir a mudança. Então o ônus à oposição se eleva, tornando irracional manter a resistência.

O segundo tipo abrange o layering, o qual instaura normas inéditas acima ou em paralelo com as antigas. Nesse caso, sua introdução desencadeia efeitos capazes de alterar o comportamento dos atores. Faz-se necessário esclarecer que o layering não promove alterações e revisões ao arcabouço em vigor. Porém, não se deve subestimá-lo, porque ele provoca "mudança substancial se as emendas modificarem a lógica da instituição ou comprometerem a reprodução estável do 'núcleo original'” (MAHONEY; THELEN, 2010, p. 17). Tal como no displacement, o engendramento do layering situa-se no espaço político e, do mesmo jeito, seus indutores são aqueles que não se sentem representados pela ordem presente. Todavia, diante da impossibilidade de implantar uma estrutura que melhor espelhe seus interesses - tendo em vista que carecem dos recursos para tal empreitada -, não lhes resta outra opção senão adotar um roteiro intrainstitucional para alçar seus objetivos. Obviamente, os partidários da conjuntura atacada buscam conservá-la em seu formato 
primitivo, afinal a desfiguração compromete sua posição. Em contrapartida, sua atuação se defronta com limitações, beirando a impotência, pois eles estão desprovidos de instrumentos através dos quais consigam barrar emendas ou modificações.

A terceira classificação compreende o drift. Ele resulta de um contexto em que as normas permanecem as mesmas, entretanto, seu efeito se transmuta devido às variações no ambiente externo. "Quando os atores escolhem não responder a tais mudanças ambientais, sua própria inação pode causar mudanças no impacto da instituição" (MAHONEY; THELEN, 2010, p. 17). Para demonstrar como isso acontece, eles mencionam os efeitos da distribuição populacional sobre os resultados de eleições democráticas e a representação política. Por exemplo, "no Japão, o Partido Liberal Democrático consolidou e manteve seu domínio na política eleitoral, em parte, negligenciando ativamente alocação dos assentos da Dieta [o parlamento] para as cidades em resposta à urbanização" (MAHONEY; THELEN, 2010, p. 17).

O último tipo acomoda o conversion. Nessa condição, as normas, embora continuem intactas, incorporam compreensões diferentes daquelas que lhes foram previamente atribuídas. Não raro uma resposta aos imperativos exógenos, essa manobra é articulada intencionalmente por atores interessados nas ambiguidades entre o que diz as regras e o entendimento do conteúdo delas. Essa falta de clareza e precisão oferece circunstâncias propícias para que os agentes com perfil revisionista se empenham pela ressignificação das bases normativas. Nota-se então que, mediante uma abordagem de dentro para fora, eles conseguem dar outra roupagem a cada elemento da arquitetura das instituições. Na prática, elas abandonam as incumbências anteriores e são direcionados a assumir "novos objetivos, funções e propósitos" (MAHONEY; THELEN, 2010, p. 17-18).

Entres os fatores responsáveis pelo conversion, Mahoney e Thelen (2010) salientam o reordenamento de forças que ocorrem em duas conjunturas específicas. Numa delas, a constelação de atores se expande em razão da entrada de outros participantes, enquanto que em outra, novas coalizões políticas são orquestradas, absorvendo mais poder. Independentemente das particularidades de ambas, há uma preferência pela preservação das antigas instituições a seu desmantelo. Imbuída de uma lógica racional, a estratégia se revela totalmente coerente, quando se consideram os altos custos de transação envolvidos na fundação de novas instituições. Longe de esse mecanismo constituir uma conduta intrínseca a agentes de maior peso, entes numa posição menos proeminente também podem fazer uso dele. Na verdade, analogamente ao layering, esse expediente é eficiente para obter ganhos devido ao déficit em ativos operacionais desses atores: "na falta de capacidade para destruir uma instituição, os contestadores institucionais podem explorar suas ambiguidades inerentes de maneiras que lhes permitam redirecioná-la para funções e efeitos mais favoráveis" (MAHONEY; THELEN, 2010, p. 18) 
Figura 3 - Tipos de mudança gradual

\begin{tabular}{|l|l|l|l|l|}
\hline & Displacement & Layering & Drift & Conversion \\
\hline Remoção das regras antigas & Sim & Não & Não & Não \\
\hline Desprezo às regras antigas & - & Não & Sim & Não \\
\hline Mudança no impacto das antigas regras & - & Não & Sim & Sim \\
\hline Introdução de novas regras & $\operatorname{Sim}$ & Sim & Não & Não \\
\hline
\end{tabular}

Fonte: adaptado de Mahoney e Thelen (2010)

A aplicação do modelo: uma análise da evolução do Conceito Estratégico da OTAN

Montado o referencial analítico, a tarefa agora será aplicá-lo ao objeto em estudo. A questão central desse exercício consiste em compreender as implicações das três versões de Conceito Estratégico (CE) adotadas desde 1991 ao acervo normativo e à evolução gradual da OTAN ao longo de duas décadas. O argumento a ser desenvolvido nessa sessão postula que a trajetória transformacional reproduz os predicados de um conversion, sendo moldada pelos conflitos de interesses entre os membros da entidade no que diz respeito às funções e à área de atuação da organização.

0 desencadeamento da mudança institucional

A elaboração do primeiro CE examinado se deu em uma conjuntura marcada por profundos eventos estruturais. À queda do Muro de Berlim se seguiu o desmonte de vários elementos que até então configuravam a Guerra Fria: o recuo do domínio da URSS sobre seus antigos satélites; a dissolução do Pacto de Varsóvia; a reunificação alemã; a retiradas das tropas soviéticas do Leste Europeu. No entanto, se, por um lado, o iminente fim do conflito Leste-Oeste coroou a OTAN como vitoriosa, por outro, desencadeou consequências sérias, com o desaparecimento da ameaça a qual ela foi encarregada de combater, a ponto de emergir questionamentos sobre sua própria razão de ser (STROMSEHT, 1991). Dizia-se àquela altura que era apenas uma questão de tempo até incorrer sobre ela o mesmo destino do Pacto de Varsóvia, ou, em caso de sobrevida, seria um arranjo anacrônico, com pouco, para não dizer, nenhuma, utilidades aos desafios vindouros (MEARSHEIMER, 1990).

Além dessas dúvidas, com a evolução do ambiente sistêmico, surgiram também novas adversidades ao sistema transatlântico. Dadas as reduzidas probabilidades de se concretizar, um ataque perpetrado pela URSS deixou de ser a preocupação primordial. Em contrapartida, a instabilidade crescente, gerada pela transição abrupta e as tensões étnicas em ebulição, emergia como a principal fonte de ameaça à organização. Entendia-se que o panorama em construção incutiria outras características nos desafios securitários, de modo que, em vez de ameaças aos moldes mais convencionais, o perigo seria resultado colateral de uma combina- 
ção de fatores que impulsionam convulsões sociais e volatilidades políticas fora das fronteiras da Aliança.

À luz da problemática institucional discutida por Mahoney e Thelen, o documento deslancha a dinâmica transformacional. No entanto, a tendência ainda não é clara naquele momento pelas próprias características de um processo gradativo. A tônica presente nele indica uma postura conservadora, que busca resguardar o status quo do fulcro regulatório principal contra investidas reformistas. Esse movimento se atesta com as várias referências aos princípios basilares da organização. Isto é, o CE mais reitera do que sugere modificações ao núcleo normativo. A título de ilustração, quando se fala da finalidade da OTAN, afirma-se que o advento de novas circunstâncias - o fim da Guerra Fria - "não muda a proposta ou funções securitárias da Aliança, mas ressalta sua validade duradoura". Portanto, "o escopo da Aliança assim como os direitos e as obrigações no Tratado de Washington permanecem inalterados” (OTAN, 1991). Nesse mesmo teor, há um endosso ao preceito da segurança coletiva resguardado no Artigo 5: "A segurança de todos os Aliados é indivisível: um ataque a um é um ataque a todos" (OTAN, 1991).

O elemento crucial aqui é a revisão na leitura da entidade sob o cenário da segurança internacional. $\mathrm{O}$ documento admite que a aderência às compreensões tradicionais não se compatibiliza com os novos desafios em virtude de sua orientação exclusiva à defesa, inspirada na lógica belicosa convencional. No entanto, as circunstâncias em tela colocam em evidência que a instabilidade "tem elementos políticos, econômicos, sociais e ambientais". Reconhece-se, portanto, que, com o advento de um ambiente global diferente daquele da ordem bipolar, o cumprimento $2 \mathrm{da}$ tarefa primordial - a proteção territorial dos países-membros - demandava uma flexibilização em sua leitura das dinâmicas securitárias. Entre outros efeitos, esse processo promove um ajuste sutil no modus operandi, que incorpora um caráter mais político do que militar, visto que "as oportunidades para alcançar os objetivos da Aliança por meios políticos são maiores do que nunca" (OTAN, 1991).

Esse expediente não invoca uma ruptura, ou mesmo, supressão com as normas pretéritas. Ele pretende uma atualização das práticas institucionais, dentro do que permite as balizas regulatórias em vigor. Dessa maneira, não acarreta, de imediato, em um desvio nas finalidades da OTAN ou a suplantação das normas fornecidas pelo TW (indicando um conversion ou layering, respectivamente), mas o acomodamento das prescrições às convenções já existentes. Frantzen (2005) consegue demostrar essa particularidade ao tratar da assimilação do gerenciamento de crises e prevenção de conflitos como atividades essenciais. Em seu artigo 31, o CE expõe a relevância dessas ferramentas no contexto vindouro: "a paz e guerra [na Europa] dependem ainda mais do que no passado da efetividade da diplomacia preventiva e do gerenciamento exitoso de crises afetando a segurança de seus membros" (OTAN, 1991). Porém, deve-se atentar a duas nuances disso. Primeiro, esses mecanismos ainda não estavam vinculados ao apaziguamento de conflitos fora da zona euro-atlântica - como seria infundido pelos debates posteriores. Logo, sua aplicação aqui se refere ao emprego das capacidades militares para fins dissuasórios 
contra ameaças estatais. Segundo, sob a ótica normativa, o significado conferido a eles se embasa nas provisões do Artigo 5. Como se previa seu uso para conter possíveis agressões, eles estavam, portanto, lastrados ao princípio da defesa coletiva.

A prevalência dessa postura pode ser explicada à luz das variáveis empregadas por Mahoney e Thelen. Ou seja, tanto as circunstâncias políticas como as regras institucionais, sobretudo, aqueles referentes à tomada de decisão, inibiram um revisionismo mais radical das normas. $\mathrm{O}$ ponto nevrálgico disso reside nas divergências entre os membros quanto aos desígnios da OTAN no pós-Guerra Fria. Enquanto o governo Bush e seus parceiros britânicos advogavam por uma reformulação que lhe conferisse atribuições para além do conceito de defesa coletiva; outros países, a exemplo da França e Espanha, defendiam sua preservação nos moldes de sua missão primária (FRANTZEN, 2005; SMITH, 2000). O pano de fundo dessas discordâncias é o desenho da arquitetura securitária da Europa após a bipolaridade e o papel da Aliança nela. Do lado norte-americano, fica evidente a preferência por um arranjo centrado na organização transatlântica. No entanto, entre os parceiros europeus, havia certa resistência à proposta, porque eles pretendiam vincular a defesa e segurança ao aprofundamento da integração, almejando estabelecer uma estrutura estratégica autônoma (BOZO, 1998; BURTON, 2018). Além disso, era do interesse de Washington agregar tarefas não contempladas pelo Artigo 5 ao repertório de funções da OTAN. Para os parceiros continentais, essas deveriam estar sob a alçada de outros organismos. A oposição se baseava no entendimento de inadequação do organismo às demandas estratégicas em ebulição: sendo derivada de uma configuração internacional muito específica, ele carecia dos meios para lidar eficientemente como os novos desafios (GHECIU, 2005). Ao fim, prevaleceu a posição do que eram favoráveis ao status quo. Não por acaso, o texto de 1991 só apresenta menções breves à participação da OTAN em tarefas não relacionadas ao Artigo 5, muito aquém da moção anglo-saxônica de disponibilizar a infraestrutura do organismo a operações de peacekeeping (FRANTZEN, 2005).

O êxito dos países antirrevisionismo reside na variável estrutural mencionada por Mahoney e Thelen, precisamente, as normas do processo decisório. Este expediente adota o consenso como princípio fundamental, o que significa que "não há votação na OTAN. As consultas ocorrem até que uma decisão aceitável para todos seja alcançada. Às vezes, os países-membros concordam em discordar sobre um assunto" (OTAN, 1991). Depreende-se disso que a agenda norte-americana representava um entrave ao processo deliberativos, em virtude das discordâncias suscitadas. Logo, fazia-se necessário alcançar um denominador comum, para que assim o CE recebesse o apoio absoluto. A julgar pelo conteúdo do CE de 1991, pode-se induzir que a costura dessa resolução se efetuou com a retirada da proposição pleiteada pelo governo norte-americano. Levantar, na ocasião, assuntos controversos, como as operações não ancoradas pela jurisprudência do Artigo 5, causaria fissuras, pondo em risco a coerência e a própria existência da instituição. Kay (1995) lembra que seu enfraquecimento não interessava aos estadunidenses, pois o esquema euro-atlântico era instrumental a sua hegemonia mundial. Ainda assim, 
havia o temor nos círculos decisórios, em Washington, de que estruturas alternativas dispersassem seus parceiros (NOETZEL; SCHREER, 2009). Essas preocupações não eram totalmente infundadas, porque outras iniciativas rivalizavam com a OTAN pela condição de centro da arquitetura securitária do continente no pós-Guerra Fria, e alguns países, a exemplo da França, sustentavam que a Organização para Cooperação e Segurança da Europa assumisse tal incumbência (GHECIU, 2005).

O CE de 1999: a evidenciação do conversion

Além de prosseguir a tendência de mudança institucional, o CE de 1999 evidencia o tipo que está se delineando. Ou seja, ele imprime à trajetória predicados de um conversion. Contudo, muito embora este tenha ganhado impulso a partir do texto do final do século XX, sua gênese remonta ao início da década. Antes mesmo da derrocada da ordem bipolar, os círculos decisórios já reconheciam a necessidade de, nas palavras do então secretário-geral Manfred Wöerner, "adaptar nossas políticas a novas tarefas" (OTAN, 1989). A tônica predominante desse discurso enfatizava a adoção de competências mais políticas do que militares como prevalecera ao longo da Guerra Fria. Para os defensores da medida, ainda que tivesse sido desenhada com o intuito de cumprir uma missão beligerante, a OTAN se mostrava apta a ampliar suas funções, sobretudo, naquele momento em que se carecia de um agente estabilizador na transição em curso na antiga esfera sob influência da URSS (GHECIU, 2005). Essa ênfase reformista já permeava o $\mathrm{CE}$ precedente. Ainda que ele não tenha produzido nenhuma inflexão substancial dadas as dificuldades elencadas, ele expôs a necessidade de se rever a postura da entidade no teatro global.

O eixo central do conversion reside nas discussões sobre o perímetro operacional e o escopo funcional do arranjo euro-atlântico (out of area). As cláusulas do TW, especificamente seu Artigo 5, trazem demarcações muito precisas a respeito dessas questões. Primeiro, ele delimita a cobertura da organização ao espaço da América do Norte e da Europa Ocidental. Segundo, estabelece que sua finalidade primária é nenhuma outra senão a defesa coletiva. No entanto, o texto de 1999 abre brecha para o relaxamento dessas duas premissas, o que cria as condições para um afastamento em relação ao paradigma primário da OTAN. Dokos (2008) argumenta que esse desvio se ampara em uma leitura dicotômica que limitava as escolhas da instituição a duas alternativas: expandir a latitude de suas atribuições e a abrangência geográfica destas ou ficar fora dos negócios (out of business). Em outras palavras, diante do esvaziamento da missão original em virtude da desagregação da ameaça soviética, a reformulação de seu alcance se coloca como imperativo para continuar sendo operante e tendo relevância no cenário global, do contrário ela estaria fadada a se tornar obsoleta.

Uma das consequências mais salientes disso se trata da relevância conferida ao gerenciamento de crises e conflitos. Essa resolução se distingue daquilo disposto no documento de 1991, que, embora tenha o inserido no catálogo de competências, não lhe confere tanta magnitude, tampouco dilata sua performance para além das definições tradicionais, 
conforme já visto anteriormente. A despeito disso, à época, já se vislumbra um reordenamento da Aliança para pacificação e estabilização a fim de, nas palavras de seu principal dirigente, "contribuir com sua logística, recursos de inteligência e até suas forças para missões de paz" (SMITH, 2000, p. 134). Nesse quesito, se deve atentar a algumas nuances da incorporação dessa atividade. Primeiro, ela se constitui em uma derivação da tarefa primária "segurança". Segundo, se colocam critérios para restringir seu emprego, de modo que seja ad hoc e não recorrente. Será visto mais adiante que esses aspectos apontam as divergências entre os membros sobre a evolução da entidade. Ainda assim, segundo Yost (2010, p. 491) "[a introdução do] gerenciamento de crises [...] constituiu um afastamento significativo das premissas da Guerra Fria quanto ao papel da OTAN".

A classificação desse fenômeno em um conversion se sustenta também em seu efeito limitado sob o marco regulatório provido pelo TW. Os esforços aplicados nesse sentido não lhe produziram atrofiamentos. $\mathrm{Na}$ verdade, quando do surgimento dos debates a respeito do tema, sustentava-se que a incorporação de competências podia prescindir modificações às normas (FRANTZEN, 2005). O processo recorreu a esse método, todavia infundindo nelas outro significado. Para isso, o expediente respalda o nexo entre a segurança do sistema atlântico e as regiões fora dele. A partir desse raciocínio se constrói uma descrição que retrata estes lugares como fonte de conturbações: "alguns países dentro e em torno da área euro-atlântica enfrentam sérias dificuldades econômicas, sociais e políticas. Rivalidades étnicas e religiosas, disputas territoriais [...] podem levar à instabilidade local e mesmo regional” (OTAN, 1999). Subestimar a gravidade desses cenários seria um equívoco, tendo em conta que seus efeitos dificilmente ficariam contidos às fronteiras do locus de origem. $\mathrm{O}$ próprio $\mathrm{CE}$ ecoa essa leitura: "as tensões resultantes podem levar a crises que afetam a estabilidade euro-atlântica, o sofrimento humano e os conflitos armados. Tais conflitos podem afetar a segurança da Aliança, transbordando para os países vizinhos, incluindo países da OTAN" (OTAN, 1999). Portanto, conforme admite Wöerner, "noções como dentro ou fora da área perderão cada vez mais sua relevância para lidar com os novos tipos de crise e conflito" (SMITH, 2000, p. 134).

Na verdade, a constelação de riscos, com natureza distinta da tônica da Guerra Fria, justificaria assumir outras incumbências, para a Aliança continuar efetiva em seu desígnio de prover segurança aos países membros. Sob essa perspectiva, as atividades mencionadas, tais quais o controle de armas e, sobretudo, o gerenciamento de crises e conflitos, se tornariam legítimas, pois seriam conduzidas em conformidade com a defesa coletiva predicada no Artigo 5. É importante destacar que a conversão disso em uma diretriz se efetua sem emendas ao referencial normativo principal: não há, ao longo do material de 1999, uma monção sequer sugerindo uma alteração do TW para acomodar as propostas. Em vez disso, o conteúdo deste é objeto de uma interpretação que ressignifica seu princípio basilar ao ponto de flexibilizar as amarras regimentais mais ortodoxas. O expediente carrega um efeito prático, porque atenua potenciais conflitos normativos e, mais importante, invalida controvérsias 
que possam surgir devido às aspirações extrarregionais. Segundo Whittmann (2009), a efetivação dessa manobra se dá pelo emprego de uma linguagem ambígua. Por exemplo, ao tratar dos limites geográficos, o material de 1999 diz que o foco da Aliança é o espaço euro-atlântico entendido como a Europa e sua periferia. Se, por um lado, isso veta as aspirações globais pleiteada por Washington e seus apoiadores; por outro, não anula a possibilidade de a entidade se engajar em missões transregionais, já que não especifica as fronteiras de sua periferia, podendo estas cobrir desde o Mediterrâneo até o Cáucaso.

A variável política é indispensável para compreender a viabilização desse tipo de mudança, pois a fonte causal do conversion reside na reverberação da Guerra da Iugoslávia no âmbito político da OTAN. O conflito se mostra responsável por moderar a oposição, já registrada aqui, de alguns membros à expansão funcional e a dilatação geográfica da atuação do organismo. Esse desdobramento resulta da alavancagem do capital político de Washington em razão de seu protagonismo na intervenção militar (BURTON, 2018; GAREY, 2019). Tal proeminência se deve à falta de coesão dos países europeus. Suas preferências divergiam quanto à abordagem para resolver a crise e os mecanismos a serem mobilizados para tal. Consequentemente, suas agendas dificultavam a costura de uma resposta comum (HENDRICKSON, 2004; MAULL, 1998). Resistente a se envolver, a Casa Branca, tanto na administração Bush quanto na Clinton, esperava que eles assumissem o gerenciamento das tensões, em conformidade com suas pretensões de aprofundar a própria atuação na segurança continental (DOVER, 2005; HENDRICKSON, 2004). No entanto, os constrangimentos materiais e as dificuldades de articulação evidenciaram a imprescindibilidade dos Estados Unidos para a preservação da estabilidade no Velho Mundo (BURTON, 2018; GAREY, 2019). Ao expor a contínua dependência da segurança continental da grande potência atlântica, o episódio beligerante na Iugoslávia torna as condições mais propícias ao conversion.

A despeito do reconhecimento coletivo da urgência em adaptar o Conceito Estratégico, não havia consenso quanto à amplitude dessa reformulação. Pelo contrário, os interesses destoavam, prevalecendo incompatibilidades em questões fundamentais. Em linhas gerais, pode-se segmentar as posturas em duas: uma a favor de uma revisão radical em termos de escopo e alcance geográfico; outra aderente à centralidade da defesa coletiva como missão e à restrição do perímetro de atuação. Em outras palavras, os países se dividiam entre uma interpretação flexível e uma compreensão ortodoxa do Artigo 5. Partidários da primeira, Estados Unidos e Grã-Bretanha reivindicavam a transformação da OTAN em uma espécie de polícia mundial, cujas responsabilidades não ficariam confinadas ao espaço euro-atlântico, tampouco às tarefas tradicionais; já a Alemanha e França subscreviam a visão mais conservadora: orientação regional com Paris dentro de normativos (SCHNEIDER, 2000). Nota-se, portanto, que duas concepções extremas concorriam: enquanto a coalizão sob tutela da potência atlântica preferia a implementação daquilo que correspondia, de certa forma, a um displacement, seus opositores defendiam o status quo. 
Conforme se percebe pela descrição acima de alguns pontos do CE de 1991, nenhuma dessas agendas conseguiu se sobrepor absolutamente a outra, de modo que o texto é produto de uma balança entre as diferentes exigências e pesam sob essa fórmula final os fatores normativos. Muito embora as circunstâncias políticas decorrentes da intervenção na Bósnia tivessem contribuído ao fortalecimento de sua posição, os EUA não podiam, no âmbito institucional, impor unilateralmente sua vontade, esperando os demais membros avalizá-la de maneira passiva. E se o tentassem, seria improvável colher algum êxito disso em virtude dos elementos constrangedores presentes no expediente decisório. Esse arranjo investe todos os participantes com poder de veto, consoante o que foi exposto. Logo, qualquer iniciativa norte-americana que colidisse com os interesses das outras partes, como era o caso, seria bloqueada. Nesse sentido, recorrer ao conversion se mostra eficiente, na medida em que se consegue atender algumas das demandas através de uma nova leitura das regras, formatada em consonância com os objetivos pretendidos dos reformistas, em vez da suplantação delas.

As reservas de atores como a França e a Alemanha aos planos do governo Clinton envolviam questões distributivas. A reconfiguração funcional da Aliança implicaria também a adequação de suas capacidades materiais. Tarefas a exemplo do gerenciamento de crises e conflitos exigiam contingentes militares com perfil mais expedicionário, dos quais a OTAN não dispunha em larga escala em decorrência de sua orientação defensiva. Por conseguinte, uma estruturação com base nesses parâmetros necessitaria de um aporte significativo de recursos. Na ótica dos opositores à iniciativa, essa alocação geraria custos, os quais evitavam assumir por causa das pressões sob os orçamentos nacionais. O contexto de dificuldades econômicas, junto com os constrangimentos institucionais advindos do processo de integração regional, tornava incompatível uma expansão de despesas, sobretudo na área militar. Na verdade, a realidade sugeria uma tendência continental de cortes nos gastos em defesa (DENI, 2007). À luz dessas considerações, é patente que a posição em prol do status quo resguardava seus apoiadores de encargos. Mantê-lo assegurava a continuidade da divisão de trabalho que satisfazia seus interesses. Consequentemente, a cautela diante das propostas estadunidenses se fazia racional, pois estas fixariam, por tabela, uma nova equação distributiva que oneraria os europeus. Em suma, subjacente aos debates sobre se a OTAN deveria ou não atuar fora do perímetro euro-atlântico e quais incumbências deveriam ser de sua competência, há a problemática sobre quem caberia o ônus desse tipo de empreitada.

O CE 2010: a sedimentação do conversion

O Conceito Estratégico "Engajamento Ativo, Defesa Moderna”, de 2010, não desviou a trajetória transformacional da OTAN dos rumos tomados quase duas décadas antes. Mesmo o CE de 2010 tendo reafirmado a orientação definida em 1999, os mesmos conflitos de interesses de antes permearam a formulação do texto. Passada quase uma década, os impasses a respeito da finalidade e da cobertura espacial ainda persistiam. 
Analogamente às deliberações pré-1999, não havia um respaldo unânime em torno dessas problemáticas. Novamente, as opiniões se fragmentavam em linhas revisionistas e conservadoras. A postura revisionista se aportava no mesmo conteúdo de outrora: prescrevia à aliança um papel securitário amplo, com um engajamento transcontinental. Por sua vez, a leitura conservadora se ancorava na permanência do desenho original da organização, centrado na defesa coletiva (YOST, 2010).

Aqui se repetia a mesma configuração de agentes vista anteriormente. Estadunidenses e britânicos, apoiados por dinamarqueses, holandeses e, até certo ponto, canadenses, patrocinavam a perspectiva globalista. A postura também recorria ao argumento de que a relevância da entidade dependia de sua projeção no cenário securitário internacional (BUNDE; NOETZEL, 2010; MARRONE, 2011). Em razão disso, o formato eurocêntrico e territorialista não se equacionava com esses imperativos (NOETZEL; SCHREER, 2012). Franceses, alemães e espanhóis encabeçavam a versão regionalista. As experiências pós-11 não deveriam de parâmetros, como a exceção. Na opinião de um partidário dessa perspectiva, fazia-se vital "retornar para casa [e] reconhecer que sua única razão de ser é a segurança europeia” (COOKER, 2008, p. 11). Essa posição se tonificou, em parte, com a recomposição gerada pela entrada de novos membros da Europa Central e do Leste Europeu. Motivados pelas ameaças inoculadas com a projeção da Rússia, a Polônia e os países do Báltico se alinhavam com a inclinação defensiva. $\mathrm{Na}$ ótica desses países, era vital priorizar a retomada do antigo foco estratégico (MACNAMARA, 2010; MARRONE, 2011; YOST, 2010).

Segundo Marrone (2011), diante de agendas tão distingas, um dos méritos do texto de 2010 reside na tentativa de buscar um meio-termo que contemplasse os interesses dos envolvidos, afinal de contas, dadas as regras que norteavam a tomada de decisão, havia poucas, para não dizer nenhuma, chances dessas preferências serem aceitas em sua totalidade. Por exemplo, se de um lado, há um endosso à defesa coletiva predicada no Artigo 5, a qual permanece sendo uma das tarefas essenciais, esta é vinculado às aspirações extrarregionais. Recorre-se, dessa maneira, a mesma manobra do documento de 1999: em vez de revogá-la como seria o caso em um displacement, submete-se a norma em tela a uma dilatação de seu significado original. Sob esse prisma, não havia nenhuma incoerência com a obrigação tradicional atuar em conflitos distantes. Pelo contrário, nas palavras do então secretário-geral Rasmussen, "a defesa territorial muito frequentemente começa longe de nossas fronteiras" (YOST, 2010). Esse tipo associação diluía as linhas conceituais entre as responsabilidades fora e dentro da jurisdição do Artigo 5. Consequentemente, tarefas como o gerenciamento de crises e conflitos não mais estariam em desacordo com esse princípio, mas se tornariam uma extensão de sua versão ampliada.

Essas deliberações colocam ainda mais relevo no conversion, visto que respalda as resoluções decidas em 1999 no tocante à abrangência inter-regional. Em particular, ao tratar do gerenciamento de crises - elevando à condição de tarefa primária - o documento não traz nenhuma limitação espacial quanto à aplicação dessa ferramenta. Usando termos 
vagos, diz que se pode emprega-la quando os eventos em questão afetem os interesses da Aliança, sem estabelecer parâmetros objetivos. $\mathrm{Ou}$ seja, ele espalda o engajamento para além do teatro continental e, por consequência, o perfil globalista advogados pelos membros reformistas. Contribui com essa validação a narrativa que vincula a vulnerabilidade do regime euro-atlântico às instabilidades advindas de fora de suas bordas. Nesse quesito, a linguagem do texto é, até mais, categórica, ao afirmar que a "instabilidade ou conflito além das fronteiras da OTAN podem ameaçar diretamente a segurança da Aliança”. O raciocínio por trás disso se inspira em uma percepção menos rígida de ameaças. Diante da natureza difusa e imprecisa destas, seu comportamento não pode ser outro exceto "envolver [externamente], portanto, sempre que possível e quando necessário" (OTAN, 2010). A despeito de as expressões "possível" e "necessário" sugerirem que a conduta não era de forma alguma irrestrita, a ênfase a esses aspectos não denota somente o acoplamento deles ao DNA da organização, mas também a irreversibilidade do caráter expedicionário desta. Em resumo, essa edição do $\mathrm{CE}$ demonstra que sua evolução como outcome resulta do acúmulo das deliberações prévias, que incrementavam o processo pouco a pouco. Mais importante, essa transformação é empiricamente comprovada quando se considera que a maioria das missões realizadas pós-2000 (ver Figura 3) nem apresenta uma natureza puramente defensiva, tampouco estão dentro das fronteiras euro-atlânticas. Fica, portanto, patente que a entidade assumiu mais a configuração dos reformistas do que a dos paladinos do status quo.

Figura 3 - Lista de Operações da OTAN pós-2000

\begin{tabular}{|c|c|c|c|}
\hline Nome da Operação & Período & Descrição & Tipo \\
\hline Operação Active Endeavour & $2001-2016$ & Contraterrorismo no Mar Mediterrânea & Segurança \\
\hline Força Internacional de Apoio á Segurança & 2003-2014 & Estruturação do aparato de segurança do Afeganistão & Segurança \\
\hline Operação Eagle Assistent & $2001-2002$ & Patrulha do espaço aéreo norte-americano & Defesa Coletiva \\
\hline $\begin{array}{l}\text { Operação Essential Harvest } \\
\text { Operação Amber Fox } \\
\text { Operação Allied Harmony }\end{array}$ & 2001-2003 & Contenção das tensões étnicas na Macedônia & $\begin{array}{l}\text { Segurança (gerencia- } \\
\text { mento de crise) }\end{array}$ \\
\hline Operação Allied Provider & Out-Dez/2008 & Contrapirataria na costa da Somália & Segurança \\
\hline Operação Allied Protector & Mar-Aug/2009 & Proteção das rotas marítimas no Chifre da África & Segurança \\
\hline Operação Ocean Shield & $2009-216$ & Contrapirataria no Chifre da África & Segurança \\
\hline Operação Unified Protector & 2011 & Derrubada do regime na Líbia & $\begin{array}{l}\text { Segurança (gerencia- } \\
\text { mento de conflitos) }\end{array}$ \\
\hline Operação Resolute Support & 2015 & $\begin{array}{l}\text { Treinamento e assistência das forças de segurança do } \\
\text { Afeganistão }\end{array}$ & Segurança \\
\hline Operação Sea Guardian & $\begin{array}{l}\text { 2016/em } \\
\text { curso }\end{array}$ & Substituta da Active Endeavour. Patrulha no Mediterrâneo & Segurança \\
\hline Missão da OTAN no Iraque & $\begin{array}{l}\text { 2018/em } \\
\text { curso }\end{array}$ & Treinamento e assistência das forças de segurança do Iraque & Segurança \\
\hline
\end{tabular}

Fonte: NATO, 2020. 
Considerações finais

As deficiências da literatura tradicional a incapacitam de explicar a evolução institucional gradativa e motivada por variáveis endógenas. Ao ancorarem suas formulações analíticas exclusivamente na força das externalidades sob o processo transformacional, tanto as abordagens teóricas das Relações Internacionais quanto as diferentes vertentes do neo-institucionalismo estreitam o exame de um fenômeno complexo e multidimensional. Essas limitações atestam a relevância do modelo proposto por Mahoney e Thelen. Os autores conseguem inovar na análise da mudança institucional, na medida em que, primeiro, a interpretam como um processo dilatado e não abrupto, resultado do acúmulo de diversos elementos; segundo, lançam mão de variáveis inerentes ao funcionamento das instituições para elucidar o objeto de estudo.

Esses referenciais permitem compreender a perenidade da OTAN. Pelo que foi exposto, sua sobrevivência se deve à transformação ocorrida ao longo de quase duas décadas. As evidências colhidas aqui apontam que a organização de 2010 pouco se assemelha àquela que emergiu vitoriosa em 1991 e inda sob a sombra da Guerra Fria. O cerne desse processo reside nas normas. Longe de serem estáticas, passaram, segundo a lógica do conversion, por uma reinterpretação. No entanto, isso não se constitui em um fenômeno autônomo. Ele espelha os conflitos de interesses entre os diversos membros da entidade. Estes se dividem em tornos de agendas que pautam a finalidade e o alcance espacial da Aliança. Sob os resultados dessas disputas pesam as variáveis adotadas por Mahoney e Thelen, as quais atuam como constrangimentos no âmbito decisório. O contexto político potencializa algumas reivindicações em detrimento de outras. Porém, isso por si só não define os outcomes, sujeitos intensamente às regras da tomada de decisão.

Essas particularidades são responsáveis por delinear a trajetória evolutiva da OTAN. Um dos aspectos evidentes é seu caráter progressivo. Cada CE incrementa essa tendência. Embora o CE de 1991 tenha trazido à tona a necessidade de adaptação, as circunstâncias à época coibiam resoluções mais concretas. De todo modo, é inquestionável que ele semeia o engendramento do conversion, Quase dez anos mais tarde, a reformulação ganha ímpeto e se torna claro o direcionamento tomado pela entidade. Ainda que a coalizão capitaneada por França e Alemanha se esforçasse em preservar o status quo, era difícil refutar que a organização já não mais se dedicava unicamente à defesa coletiva. Mesmo que fossem efetuadas de maneira ad hoc, as atividades fora dos parâmetros originais passaram a fazer parte do repertório funcional. Ou seja, a OTAN havia se habilitado a elas formalmente. Por fim, o CE de 2010 confirma a mudança. Apesar de em suas tratativas se repetirem os mesmos dilemas, não há recuos ou desmanche às deliberações prévias. Dificilmente, seria possível isso, porque os textos pretéritos fixaram um curso de cujo desvio imputariam elevados custos aos atores políticos. Por fim, é importante salientar que a classificação do processo estudado em conversion não é arbitrária. As revisões na função e no alcance geográfico seguem os mecanismos que configura esse tipo. Obviamente, isso não descarta que outras categorias 
se manifestam ou, mesmo, que se conteste esse argumento. Mas, cabe a outras estudos empreender tal esforço para aprimorar agenda de pesquisa sobre mudança institucional.

Referências

AXEROLD, R; KEOHANE, R. Achieving cooperation under anarchy: strategies and institutions. World Politics, v. 38, n. 1, p. 226-254, 1985.

BOZO, F. France. In: BRENNER, M. NATO and Collective Security. New York: Macmillan Press, 1998.

BURTON, J. NATO's durability in a post-Cold War world. Albany: State University of New York, 2018.

BUNDE, T; NOETZEL, T. Unavoidable tensions: the liberal path to global NATO. Contemporary Security Policy. [s.l], v. 31, n. 2, p. 295-318, 2010.

COOKER, C. Why NATO should return home? The case for a twenty-first century Aliance. RUSI Journal. [s.l], v. 153, n. 4, p. 6-11, 2008.

DENI, J. Alliance management and maintenance: restructuring NATO for the 21st century. Hampshire: Ashgate, 2007.

DOKOS, T. Countering the proliferation of weapons of mass destruction: NATO and the EU options in the Mediterranean and the Middle East. London: Routledge, 2008.

DOVER, Robert. The EU and the Bosnian Civil War 1992-95: The Capabilities Expectations Gap at the Heart of EU Foreign Policy. European Security. [s.l], v. 14, n. 3, p. 297-318, 2005.

FRANTZEN, H. NATO and peace support operations 1991-1999: policies and doctrines. Oxon: Frank Cass, 2005.

GAREY, J. The US Role in NATO's Survival After the Cold War. Cham: Palgrave Macmillan, 2019

GHECIU, A. NATO in the New Europe: the politics of international socializations after the Cold War. Stanford: Stanford University Press, 2005

GLASER, C. Realists as optmistis: cooperation as self-help. International Security. [s.l], v. 19, n. 3, p. 50-90, 1994.

GRIECO, J. Anarchy and the limits of cooperation: a realist critique if the newest liberal institutionalist. International Organization. [s.l], v. 42, n. 3, pp. 485-507, 1988

HENDRICKSON, R. Leadership at NATO: secretary-general Manfred Woerner and the Crisis in Bosnia. Journal of Strategic Studies. [s.l], v. 27, n. 3, p. 508-527, 2004.

KAY, S. NATO and the United States. In: PAPACOSMA, V; HEISS, M. (eds), NATO in the post-Cold War era: does it have a future. Hampshire: MacMillan Press, 1995, p. 151-178.

KEOHANE, R. After hegemony: cooperation and discord in the world political economy. Princeton: Princeton University Press, 1984.

KEOHANE, R.; MARTIN, L. The Promise of Institutionalist Theory. International Security. [s.l], v. 20, n. 1, p. 39-51, 1995.

JERVIS, Robert. Realism, neorealism, and cooperation: understanding the debate. International Security, v. 24, n. 1, p. 42-63, 1999.

MCCALLA, R. NATO's persistence after the Cold War. International Organization, v. 50, n. 3, p. 445-475, 1996

MACNAMARA, S. NATO Summit 2010: time to turn words into actions. Background, n. 2498, 2010.

MAHONEY, J; THELEN, K. A theory of gradual institutional change. In: MAHONEY, J; THELEN, K. (eds). Explaining institutional change: ambiguity, agency and power. Cambridge: Cambridge University Press, 2010.

MARRONE, A. The Equilibrium of the 2010 NATO Strategic Concept, The International Spectator: Italian Journal of International Affair. [s.l], v. 46, n. 3, p. 93-111, 2011.

MAULL, H. Strategic outlook: compatibilities and incompatibilities. In: BRENNER, M. NATO and Collective Security. New York: Macmillan Press, 1998. 
MEARSHEIMER, J. Back to the future: instabilbity in Europe after the Cold War. International Security. [s.l], v. 15 , n. 1, p. 5-56, 1990

MEARSHEIMER, J. The false promise of international institutions. International Security. [s.l], v. 19, n. 3, p. 5-49, 1994.

NATO. Operations and missions: past and presente. NATO. 4 jun. 2020. Disponível em: https:// www.nato.int/cps/en/natohq/topics_52060.htm. Acesso em: 15 jul. 2020

NOETZEL, T; SCHREER, B. Does a multi-tier NATO matter? The Atlantic allaince and the process of strategic change. International Affairs. [s.l], v. 85, n. 2, p. 211-226, 2009.

NOETZEL, T; SCHREER, B. More flexible, less coherent: NATO after Lisbon. Australian Journal of International Affairs. [s.l], v. 66, n. 1, p. 20-33, 2012.

OYE, K. Explaining cooperation under anarchy: hypothesis and strategies. World Politics. [s.l], v. 38 , n. 1 , p. $1-24,1985$

OTAN. Address to the North Atlantic Council. OTAN. Bruxelas, abr. 1989. Disponível em: https://www.nato.int/docu/speech/1989/s890404a_e.htm. Acesso em: 15 mar. 2020

OTAN. The Alliance's New Strategic Concept. Londres. OTAN. 7 nov. 1991. Disponível em: https://www.nato.int/cps/en/natohq/official_texts_23847.htm. Acesso em: 15 mar. 2020.

OTAN. The Alliance's Strategic Concept. OTAN. Washington, 24 abr. 1999. Disponível em: https://www.nato.int/cps/ie/natohq/official_texts_27433.htm. Acesso em: 15 mar. 2020.

OTAN. Strategic Concept Active Engagement, Modern Defence. OTAN. Lisboa, 20 nov. 2010. Disponível em: https://www.nato.int/nato_static_fl2014/assets/pdf/pdf_publications/20120214_strategic-concept-2010-eng.pdf. Acesso em: 15 mar. 2020.

SCHNEIDER, P. The Evolution of NATO: the Alliance's Strategic Concept and its predecessor, 1949-2000. 2000. 134 f. Dissertação (Mestrado) - Arts in National Security Affairs, Naval Post Graduate School, Monterey, 2000.

SMITH, M. NATO in the first decade after the Cold War. Sandhurst: Springer, 2000.

SCHWELLER, R; PRIESS, D. A tale of two realisms: expanding the institutions debate. Mershon International Studies Review, v. 41, n. 1, p. 1-32, 1997.

STROMSEHT, J. The North Atlantic Treaty and European Securitu after the Cold War. Cornell International Law Jorunal. [s.l], v. 24, n. 3, p. 479-502, 1991.

WALT, S. The Origins of Alliances. Ithaca: Cornell Univeristy Press. 1987.

WALTZ, K. Theory of International Politics. Reading: Addison Wesley Publishing Company. 1979.

WHITTMANN, K. Towards a new Strategic Concept for NATO. Rome: NATO Defense College, 2009

YOST, D. NATO's evolving purposes and the next Strategic Concept, International Affairs. [s.l], v. 86, n. 2, p. 489-522, 2010. 